1. Lindley, P. F. and Woodward, P. J. Chem. Soc. 1966123.

2. Newns, D. M. and Staveley, L. A. K. Chem. Rev. 66 (1966) 267.

3. Pistorius, C. W. F. T. Z. Krist. 155 (1961) 291.

4. Arell, A. Ann. Acad. Sci. Fennicae, A $V I$, Physica 1962 No. 100.

5. Reinsborough, V. C. and Wetmore, F. E. W. Australian J. Chem. 20 (1967) 1.

6. Maziers, C. and Hoff, J. Compt. Rend. 256 (1963) 2620.

7. Tahvonen, P. E. Ann. Acad. Sci Fennicae, A I. Math.-Phys. 1947 No. 43.

8. Tahvonen, P. E. Ann. Acad. Sci Fennicae, A I. Math.-Phys, 1947 No. 44.

9. Strømme, K. O. Acta Chem. Scand. 23 (1969) 1616.

10. Strømme, K. O. Acta Chem. Scand. 23 (1969) 1625

11. Strømme, K. O. Acta Chem. Scand. In press.

Received April 30, 1970.

\section{On the Crystal Structure of Lithium Nitrate above Room Temperature}

K. O. STRØMME

Department of Chemistry, University of Oslo, Blindern, Oslo 3, Norway

M ost univalent metal nitrates can exist in several distinctly different poly. morphic forms at atmospheric pressure. ${ }^{1}$ At ordinary temperature lithium and sodium nitrate have a rhombohedral crystal structure $^{2}$ of the (ordered) calcite-type ${ }^{\mathbf{3}, 4}$ shown in Fig. 1. On heating, sodium nitrate transforms gradually into a rhombohedral, orientationally disordered structure stable above $276^{\circ} \mathrm{C}$. The nitrate groups seem to occupy alternatively both disordered calcite- and aragonite-type positions in the high-temperature phase.

A slight discontinuity in the ultra-violet spectrum of lithium nitrate was observed at $170^{\circ} \mathrm{C}^{\circ}$ and ascribed to a previously undiscovered transition. Also, an anomaly in the electric resistivity has recently been detected at $230^{\circ} \mathrm{C}^{7}$ No phase change is, however, apparent from X-ray diffraction measurements ${ }^{2,8}$ or thermal observations."
This may not, however, exclude the possibility of orientational disorder in lithium nitrate at elevated temperatures, for example similar to that suggested for sodium nitrate at intermediate temperatures. ${ }^{5}$ Accurate $C p$-data are apparently not available. To be realistic a statistical model of a structure should give rise to instantaneous configurations which involve only acceptable intermolecular separations. It seemed reasonable for the present case to use the model recently put forward for $\mathrm{NaNO}_{3}-\mathrm{I}^{5}$ and $\mathrm{KNO}_{3}-\mathrm{I},{ }^{10}$ wherein the nitrate groups were shown to occupy disordered aragonite- and calcite-type positions, alternatively.

Values of interatomic distances calculated on this basis are listed in Table 1 . The $\mathrm{Li}-\mathrm{O}$ distance obtained assuming an oxygen atom in $(x, x, 0)$ was used to estimate an approximate value of the $z$-parameter of oxygen (and nitrogen, assuming the anion to be planar) in an aragonite type position (O in $(x / 2, x, z))$. The melting point of lithium nitrate is reported to be $253.1^{\circ} \mathrm{C}$. The short $\mathrm{Li}-\mathrm{O}$ distance indicates a strong (electrostatic) attraction between the metal ion and the nearest oxygen atoms. The separation is, however, somewhat longer than the sum of the ionic and van der Waals radii. ${ }^{11}$ The $\mathrm{Li}-\mathrm{N}$ separations are relatively large, possibly in part due to the electrostatic repulsion between the cations and the nitrogen atoms. Similar results were also noted for sodium ${ }^{5}$ and potassium nitrate. ${ }^{10}$

Of the twelve listed values for $\mathrm{O}-\mathrm{O}$ separations at each temperature, only six exceed $2.8 \AA$, the generally accepted value of the $\mathrm{O}-\mathrm{O}$ contact distance. ${ }^{10}$ The remaining six values are seen to be considerably shorter than $2.8 \AA$ and will therefore be assumed to be excluded at equilibrium. Inspection of Table 1 shows that two neighbouring anions cannot occupy disordered calcite-type positions (i.e. not equivalent according to space group $R \overline{3} c$ ), nor can they be situated in disordered aragonite-type positions (not equivalent according to $R \overline{3} c)$. A nitrate group occupying a calcite-type position may, however, be located close to a nitrate ion in an aragonite-type position, etc. Thus apparently, disordered arrangements of the nitrate groups may occur. However, consideration of an assembly of molecules in the lattice shows that the structure must be of the ordered calcite-type (all anions equivalent according to $R \overline{3} c$; Fig. 1) at any temperature. 
Table 1. Intermolecular distances in lithium nitrate. Numbers in parentheses refer to $20^{\circ} \mathrm{C}$, the others to $251.4^{\circ} \mathrm{C} .^{7}$ Basic parameter values are: $d(\mathrm{NO})=1.25 \AA, 3,4 a=4.729 \AA(4.692 \AA)$, $c=15.577 \AA(15.206 \AA),{ }^{7}$ hexagonal axes according to space group $R \overline{3} c$. The uncertainty in the values of the interatomic distances involving nitrate in calcite-type positions is probably of the order of some thousands of an Ángström. For the other distances the uncertainty is somewhat larger. $\mathrm{C}=$ calcite-type oxygen position. $\mathbf{A}=$ aragonite-type oxygen position. $\mathbf{E}=$ crystallographically equivalent nitrate groups. $\mathrm{N}-\mathrm{E}=$ crystallographically nonequivalent nitrate groups.

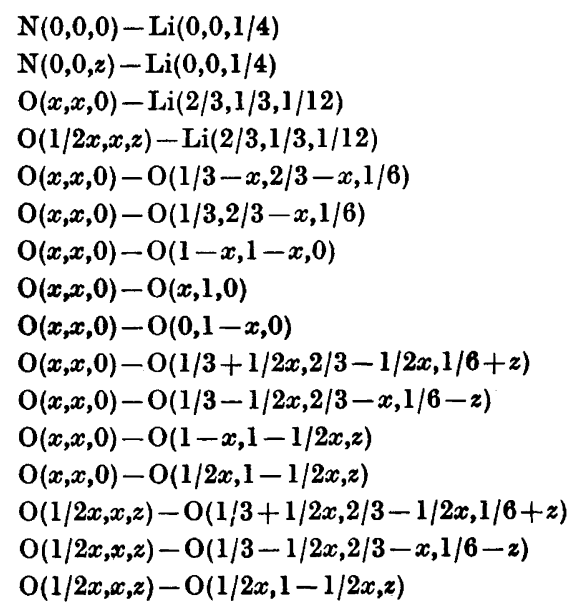

\begin{tabular}{|c|c|}
\hline Distance (A) & $\begin{array}{l}\text { Sym.rel. } \\
\text { according to } \\
R \overline{3} c\end{array}$ \\
\hline $3.27(3.17)$ & \\
\hline $2.189(2.154)$ & \\
\hline $2.189(2.154)$ (ass.) & \\
\hline $2.936(2.878)$ & $\mathrm{CC}(\mathrm{E})$ \\
\hline $2.656(2.592)$ & $\mathrm{CC}(\mathrm{N}-\mathbf{E})$ \\
\hline $2.229(2.192)$ & $\mathrm{CC}(\mathrm{N}-\mathrm{E})$ \\
\hline $3.479(3.442)$ & $\mathrm{CC}(\mathrm{N}-\mathrm{E})$ \\
\hline $3.05(3.02)$ & $\mathrm{CC}(\mathrm{E})$ \\
\hline $3.12(3.06)$ & CA \\
\hline $2.40(2.33)$ & CA \\
\hline $2.50(2.46)$ & CA \\
\hline $3.07(3.04)$ & CA \\
\hline $2.94(2.88)$ & $\mathbf{A A}(\mathbf{E})$ \\
\hline $1.98(1.91)$ & $\mathbf{A A}(\mathbf{N}-\mathbf{E})$ \\
\hline $2.56(2.53)$ & $\mathbf{A A}(\mathbf{E})$ \\
\hline
\end{tabular}

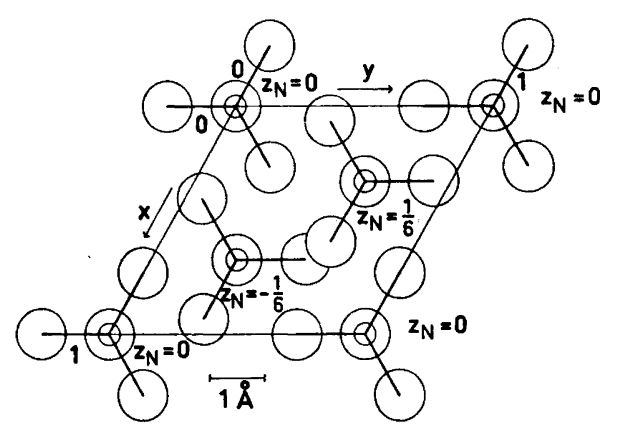

Fig. 1. The ordered calcite-type structure of lithium (sodium) nitrate viewed along the hexagonal $c$-axis. The nitrate groups are placed in planes perpendicular to the $c$-axis with the nitrogen atoms in $(0,0,0),(0,0, \pm 1 / 2),(1 / 3,2 / 3$, $-1 / 3) \quad(1 / 3,2 / 3,-1 / 3 \pm 1 / 2), \quad(2 / 3,1 / 3,1 / 3)$, $(2 / 3,1 / 3,1 / 3 \pm 1 / 2)$, etc., whereas the lithium ions are located in centres of symmetry equally distant from two and two nitrate groups on the three-fold symmetry axes, respectively. Small circles: $\mathrm{Li}$, large circles: $\mathrm{N}$ and $\mathrm{O}$ (arbitrary scale).
If a nitrate group is situated at the origin as shown in Fig. 1, the next neighbour anion at $(1,1,0)$ must be placed as shown (i.e. in an equivalent position). It can not be in the alternative calcite-type position or in any of the two indicated aragonite-type positions according to the basic requirements used here. This applies also to the nitrate groups at $(1,0,0)$ and $(0,1,0)$, considering the interaction with that centred about $(1,1,0)$; etc. Accordingly, the next neighbour nitrate groups situated in a plane perpendicular to the $c$-axis must occupy ordered calcite-type positions if one nitrate group is assumed to be in this type of position. This may be stated more absolutely by noting that a pure aragonitetype arrangement of the anions is not possible on the present basis. Thus if the anion at the origin has an oxygen atom in $(x, x / 2, z)$, the anion at $(1,0,0)$ must occupy the alternative aragonite-type position, (O in $(1+x / 2, x,-z))$. The nitrate group at $(1,1,0)$ can then not occupy an aragonitetype position without producing too short $\mathrm{O}-\mathrm{O}$ contacts.

Assuming the molecule in $(0,0,0)$ to be in a calcite-type position, we consider next 
the nearest neighbour anion interaction. The anion at $(2 / 3,1 / 3,-1 / 6)$ must occupy the ordered calcite-type position, relative to that at the origin, or an aragonite-type position. However, because of the interaction with the next neighbours of this nitrate group, these anions must also occupy ordered calcite-type positions. A similar result applies likewise to the nitrate group at $(1 / 3,2 / 3,1 / 6)$ and its next neighbours, and so forth. As a result the present model yields a positionally ordered equilibrium structure of solid lithium nitrate at any temperature.

It may be noted that a nitrate group is $a$ priori expected to occupy either a calciteor an aragonite-type position, i.e. a special position in the unit cell, for symmetry reasons, neglecting the interaction with the remaining lattice. On the other hand, if the system possesses some orientational disorder, the instantaneous equilibrium configuration may deviate from the statistical symmetry $(R \overline{3} c)$. To a smaller extent this may be expected to apply to the configuration of the cations too. As a result, the positions of the nitrate groups may deviate instantaneously somewhat from the special positions mentioned above. Such deviations are probably not sufficient to make the unacceptable $\mathrm{O}-\mathrm{O}$ distances of Table 1 accessible to the system at equilibrium, if the $\mathrm{Li}-\mathrm{O}$ distances etc. are to be of reasonable lengths. This remains valid even if the small uncertainty in the $z$-parameter value used for oxygen in an aragonite-type position is incorporated. Furthermore, only four of the six quoted $\mathrm{O}-\mathrm{O}$ distances less than $2.8 \AA$ are sufficient to derive the present result. Also, the ordered calcitetype $\mathrm{O}-\mathrm{O}$ contact distances are actually significantly longer than $2.8 \AA$, being, however, considerably less than those observed in the ordered phases of sodium and potassium nitrate.

According to the above discussion any orientational disorder in solid lithium nitrate is expected to be small or zero at equilibrium. This should not, however, exclude the possibility that the nitrate groups may reorient about the $c$-axis from one position to the equivalent orientation at higher temperatures. At a given moment the fraction of reorienting molecules is expected to be small ${ }^{12}$ (or zero).

Acta Chem. Scand. 24 (1970) No. 4
1. Newns, D. M. and Staveley, L. A. K. Chem. Rev. 66 (1966) 267.

2. Kracek, F. C., Barth, T. F. W. and Ksanda, C. J. Phys. Rev. 40 (1932) 1034.

3. Cherin, P., Hamilton, W. C. and Post, B. Acta Cryst. 23 (1967) 455.

4. Felty, E. J. Diss. Abstr. 24 (1964) 4423.

5. Strømme, K. O. Acta Chem. Scand. 23 (1969) 1616.

6. Rhodes, E. and Ubbelohde, A. R. Proc. Roy. Soc. Ser. A. 251 (1959) 156.

7. Fermor, J. H. and Kjekshus, A. Acta Chem. Scand. 23 (1969) 1581.

8. Fischmeister, H. F. J. Inorg. Nucl. Chem. 3 (1956) 182.

9. Riccardi, R. and Sinistri, C. Ric. Sci. Rend. Sez. A 8 (1965) 1026.

10. Strømme, K. O. Acta Chem. Scand. 23 (1969) 1625.

11. Pauling, L. Nature of the Chemical Bond, Cornell 1960.

12. Darmon, I. and Brot, C. Mol. Cryst. 2 (1967) 301.

Received April 30, 1970.

\section{Volatile Cor Sron $_{\text {on }}$ of the Cephalic Marking Secretion of Male Bumble Bees BERTIL KULLENBERG}

Ecological Station of the University of Uppsala, S-380 61, Ölands Skogsby, Sweden

GUNNAR BERGSTRöM and
STINA STÄLLBERG-STENHAGEN

Institute of Medical Biochemistry, University of Göteborg, S-400 33 Göteborg, Sweden

Volatile compounds present in the secre. tions emanating from glands in the heads of male bumble-bees have been studied in 13 species of the genus Bombus and 6 species of the genus Psithyrus, the last mentioned being the so-called cuckoo bumble-bees which parasitize the nests of Bombus. The secretion is used during the flying season-July to September, depending on species - to mark different objects in the flying territories, a very characteristic behaviour. It has been found that 